\title{
The Battle for the Streets of NSW
}

\section{Maged Ishak and Bert Groen}

$\mathrm{P}$ roposals are floated from time to time to solve the perceived problem of a link between juveniles hanging out in public places such as streets, shopping centres, parks, and on public transport, and the incidence of juvenile crime. In 1994, the NSW Government proposed to solve this problem with Part 3 of the Children (Parental Responsibility) Act 1994 (NSW). By virtue of this proposal police were given the ability to remove juveniles from public places if police believed, on reasonable grounds, that the person in question was under the age of sixteen and was not supervised or under the control of a responsible adult. The efficacy of the proposal was to be tested by way of operation of pilot schemes in the Local Government Areas of Orange and Gosford for a period of one year beginning on 13 March 1995. The Act (Section 16) provided for an evaluation of the pilot scheme to be done as soon as possible a year from the date of assent in order

To ascertain whether the policy objectives of the Act remain valid and whether the terms of the Act remain appropriate for securing those objectives.

Consultants were appointed in June 1996 to evaluate the legislation and to report to the Parliamentary Evaluation Committee on the Children (Parental Responsibility) Act 1994 (NSW) (Evaluation Committee).

In evaluating the pilot schemes the consultants bewailed the problem 'of having no reliable objective data to assist them in determining whether the Act works or is likely to work' (Evaluation Committee, 1997:11). Instead the consultants had to rely 'to a considerable extent upon the subjective views and experiences of individuals, organisations and groups who have their own interests in the Act and young people, as well as the limited research in this area' (Evaluation Committee, 1997:34). The consultants undertook extensive consultations with local police, local councillors, local community organisations, government organisations, parents and youths among many others before recommending that Part 3 of Children (Parental Responsibility) Act 1994 (NSW) be repealed (see Evaluation Committee, 1997:Appendix C). However, it is suggested that without an examination of both subjective views and objective data, any evaluation lacks completeness.

This paper addresses the lack of objective data that bedevilled the consultants. This is done by analysing available juvenile crime data for Orange and Gosford before during and after the introduction of the pilot schemes.

Maged Ishak is a Lecturer in Statistics and Bert Groen is a Lecturer in Law in the School of Business, Central Coast Campus, University of Newcastle. 


\section{Background to the Passing of the Legislation}

To understand the push for the passing of Part 3 of the Children (Parental Responsibility) Act 1994 (NSW) is to understand the atmosphere that prevailed in NSW in the late 1980's into the early 1990's. Much legislation is driven by perception and in NSW there were a number of widely held community perceptions with regard to juvenile crime. As noted by the (Youth Justice Coalition, 1990:51), these perceptions included the beliefs that a juvenile crime wave was about to engulf the community, that juveniles committed disproportionately large numbers of serious personal and property offences, that new legislation and programs had resulted in an increase in juvenile crime, that society was getting soft on delinquents, and that tougher institutions and harsher penalties would help to curb juvenile crime. It did not matter that many of these perceptions could be debunked ${ }^{1}$ or that juvenile crime was often invoked as an important signifier of a general malaise in morality, discipline, economy and freedom. What was more important was the flavour of the times, a flavour that can be encapsulated from this quote in The Bulletin (as quoted in Youth Justice Coalition, 1990:137):

As street crime figures rocket, the spectre of a lawless society is looming with Australians increasingly at risk of being robbed, mugged or raped. Reporting from the front lines in city and country, Martin Warneminde describes how many people are planning to strike back because they believe the police are tied down by politicians and pressure groups more concerned for the care of the villain than the victim.

The community of NSW felt something had to be done and it seemed that they might be prepared to take matters into their own hands. Recent studies had also drawn a causal link between family factors and juvenile involvement in crime. Baker (1998:3-4) reports that studies in the 1980's and early 1990's had shown that family factors such as poor parental supervision, parental rejection of the child, lack of involvement with the child, and inconsistent and erratic discipline were very strong predictors of a juvenile's involvement in crime. It was against this background that the NSW Coalition Government decided to act.

1 See, for example, Parliament of NSW (Legislative Council) (1992:12-13) and NSW Department of Juvenile Justice (1996:6). 


\section{The 1994 Legislation as it Related to the Pilot Schemes.}

The Children (Parental Responsibility) Act 1994 (NSW) was enacted to address the incidence of juvenile crime and the perceived failure of parents and guardians to take responsibility for their children. Specifically, as indicated by the Second Reading Speech, the legislation had five objectives:

- to prevent and reduce juvenile crime;

- to protect citizens from violence and interference with property;

- to make families responsible regarding the criminal behaviour of their children and to make them share the responsibility for their rehabilitation and punishment;

- to address the role of family dysfunction and inadequate and neglectful parenting in causing juvenile crime; and

- to protect children where there is a likelihood that they may commit a crime or be exposed to some risk (Evaluation Committee, 1997:18).

Part 3 of the Act, among other parts, was enacted in pursuit of these objectives. It was popularly conceived, and probably still is, that Part 3 introduced a youth curfew. This was a misconception. It is instructive, therefore to look at what, in fact, Part 3 of the Act provided for.

Section 12 of the Children (Parental Responsibility) Act 1994 (NSW) allowed NSW police to do the following:

- to ask a person his or her name and age, and his or her parent's or carer's residential address;

- $\quad$ to remove and escort a person from any public place to the parent's or carer's residence but if such address was not known or it was not reasonably practicable to do so, to remove and escort a person from any public place to a place of refuge prescribed by the regulations; and

- to use reasonable force to remove and escort a person.

A police officer could not remove and escort a person from a public place unless the police officer could establish four things (Sections 11(1) and 12(4)), namely that:

- the person was in a public place;

- the police officer believed on reasonable grounds that the person was a child of or under 15 years of age and was not subject to the supervision or control of a responsible adult;

- the police officer knew or had requested the person's name and age and his or her parent's or carer's residential address; and 
- the police officer considered that removing and escorting the person from a public place would reduce the likelihood of a crime being committed or of the person being exposed to some risk.

Section 12(3) stated that a police station could not be a prescribed place of refuge. Under section 12(7) a police officer had an obligation to notify the Director-General of any child that the police officer had reasonable grounds to suspect had been abused. These requirements, together with the requirement that the legislation be reviewed within one year of its assent, were conditions that the NSW Opposition insisted upon before giving their assent to the legislation. The legislation also provided that police officers had to notify parents or carers, if the parent or carer was known and notification was practicable, that the person had been removed and escorted to a place other than the parent's or carer's residence (Section 12(5)).

Part 3 of the Act was introduced in the Local Government Areas of Orange and Gosford for a one-year period commencing 13 March 1995.

\section{Why Orange and Gosford Were Chosen for the Pilot Schemes}

The city of Orange was selected as a pilot scheme area because there was a public perception of a problem with youth crime. According to the Evaluation Committee (1997:37 and Appendix C), elderly people had been complaining to police about an increased congregation of young people in the streets, particularly at night, and at so-called 'hot spots'. A community plan prepared for Orange detailed considerable community concern, particularly among older people and women, about personal safety in some public spaces, about young people menacing other people going about their normal business, about bag snatchers, and about young people 'hanging around' (pp. 18, 38 and Appendix C). There was also a general feeling that parents were disempowered by the law as it then stood in their dealings with children (pp. 19, 38 and Appendix C).

Police from the Gosford Local Government Area were perplexed about the selection of Gosford for the pilot study. While there had been a problem with youths hanging around in public places two and a half years prior to the institution of the pilot scheme, the problem had been at Wyoming shopping centre, not at Gosford. Police reported that there was no juvenile crime wave in Gosford (p. 49 and Appendix C). Gosford is, however, an area that is characterised by a relatively high proportion of people over the age of sixty. It may have been the fear expressed by people in this age category that led to the selection of Gosford as the subject for the pilot study. Again, parents reported that they felt disempowered with regard to their children by the prevailing law (p. 49 and Appendix C). 


\section{Evaluation the Impact of the Legislation}

To evaluate whether Part 3 of the Children (Parental Responsibility) Act 1994 (NSW) has achieved the Act's stated aim of reducing juvenile crime the authors have recently undertaken a study of the rate of juvenile crime in Gosford and Orange in NSW.

Two sets of statistics were examined in the study - statistics from the NSW Bureau of Crime Statistics (BCS) and statistics from the NSW Department of Juvenile Justice (DJJ). The statistics from the BCS proved to be more relevant than those from the DJJ in that they recorded all juvenile offences whether or not the offence resulted in a court appearance, whereas the statistics from the DJJ only recorded juvenile crime resulting in a court appearance. Nevertheless both sets of data were considered in the examination of, in particular, overall juvenile offence rates, juvenile offence rates by gender, and juvenile offence rates by age.

The data were analysed in twelve-month blocks, from April of one year to March of the next, to coincide with the twelve-month period of the pilot schemes. The study is a retrospective comparative study of changes in juvenile levels of crime following the application of the Children (Parental Responsibility) Act 1994 (NSW) in 1995. The study compares juvenile offence rates in three nonoverlapping periods:

- the pre-legislation period, 1992-1995;

- the period when the legislation was in force, 1995-1996;

- $\quad$ the post- legislation period, 1996-1998.

Three variables were considered:

- overall juvenile offence rates;

- juvenile offence rates by gender; and

- juvenile offence rates by age.

Juvenile rates of crime were computed by dividing the number of juvenile offences by the total number of juveniles from figures obtained from the Australian Bureau of Statistics relevant to the different variables and specific geographical areas. In addition to Gosford and Orange data NSW data as a whole were analysed to provide a comparison with an area where the legislation was not in force.

It is worth noting that in 1994 the method of recording crime by NSW police was changed from a manual process to a computer process. As a result statistics recorded for 1994, the transition period, are unreliable for research purposes. To overcome this problem a statistical time series technique was applied from 1992 
until 1999 in order to provide estimates for overall juvenile crime, juvenile offences by gender, and juvenile offences by age for $1994^{2}$.

\section{Results}

Overall juvenile offence rates

The overall juvenile crime rates for NSW, Gosford and Orange from 1992 to 1999 using NSW Bureau of Crime Statistics figures is presented in Figure 1.

Figure 1: Juvenile Offences Rate (overall)

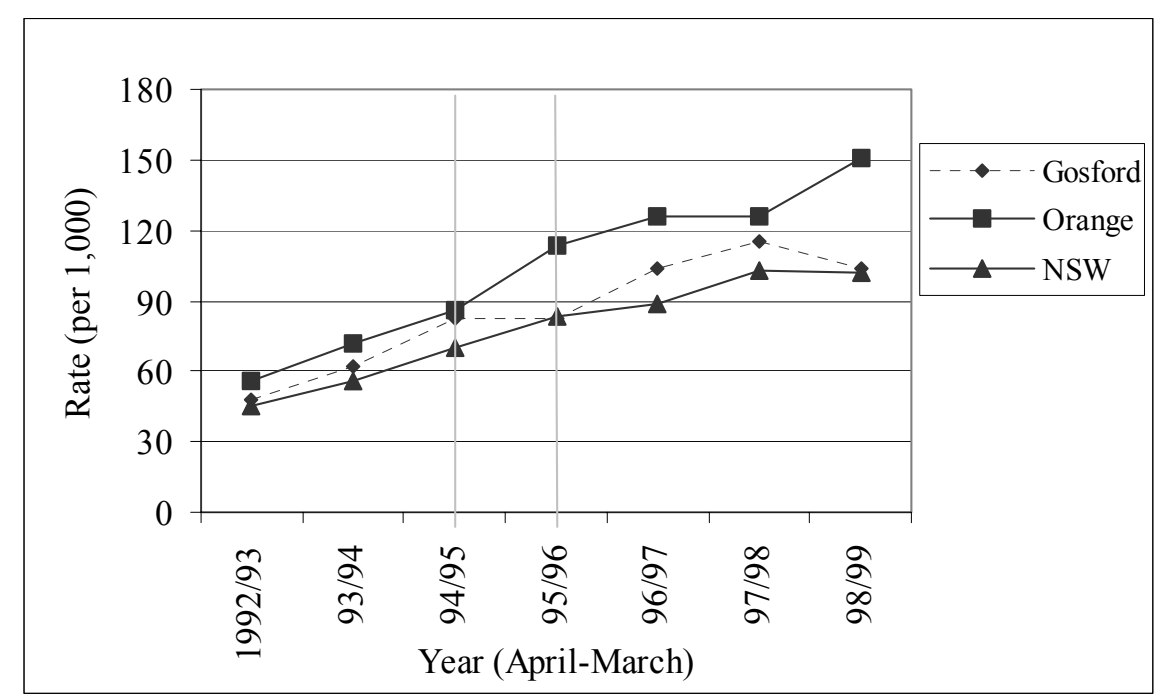

Source: BCS data.

The figures indicate that there was an overall steady increase in juvenile crime from 45.25 per thousand of juvenile population between the ages of 10 to 18 in 1992 to 101.64 per thousand in 1999 in NSW. The overall crime rate in Gosford and Orange showed a similar trend of increase over that time period. However, the trend in Gosford was characterised by a drop in the rate of crime in the period when the Act was in force (1994/95 - 1995/6). The difference in the rate of crime during this period was found to be significantly different than the rate in the periods before and after the Act was introduced.

The pattern in Orange indicated a generally higher level of juvenile crime rate when compared to the NSW and Gosford rates, especially from 1994/1995 onward. In contrast with the results from Gosford there was no drop in the rate of crime in 1995/6 in Orange or NSW. The results with regard to Orange, however,

2 An interpolation using polynomial regression techniques was used. Further details of the research methodology used are available from the authors upon request. In this paper, the significance of differences in crime rates is determined at the five per cent level. 
ought to be treated with caution, as the number of recorded incidents in Orange was small. The recording of one or two extra incidents in Orange in any one-year can affect the resulting pattern.

The conclusion that may be drawn from this analysis is that the pilot scheme seems to have been successful in Gosford but was not in Orange.

\section{Juvenile offence rates by gender}

Figure 2 shows juvenile offence rates by gender in Gosford from 1992 until 1999 using NSW Bureau of Crime Statistics data. The figure indicates a significant drop in the increasing trend of crime rates for males in 1995/6 as compared to the previous and following periods. However, there was no significant difference in crime rates for female juveniles during the $1995 / 6$ period when compared to the prior and subsequent periods.

Figure 2: Juvenile Offence Rates by Gender in Gosford

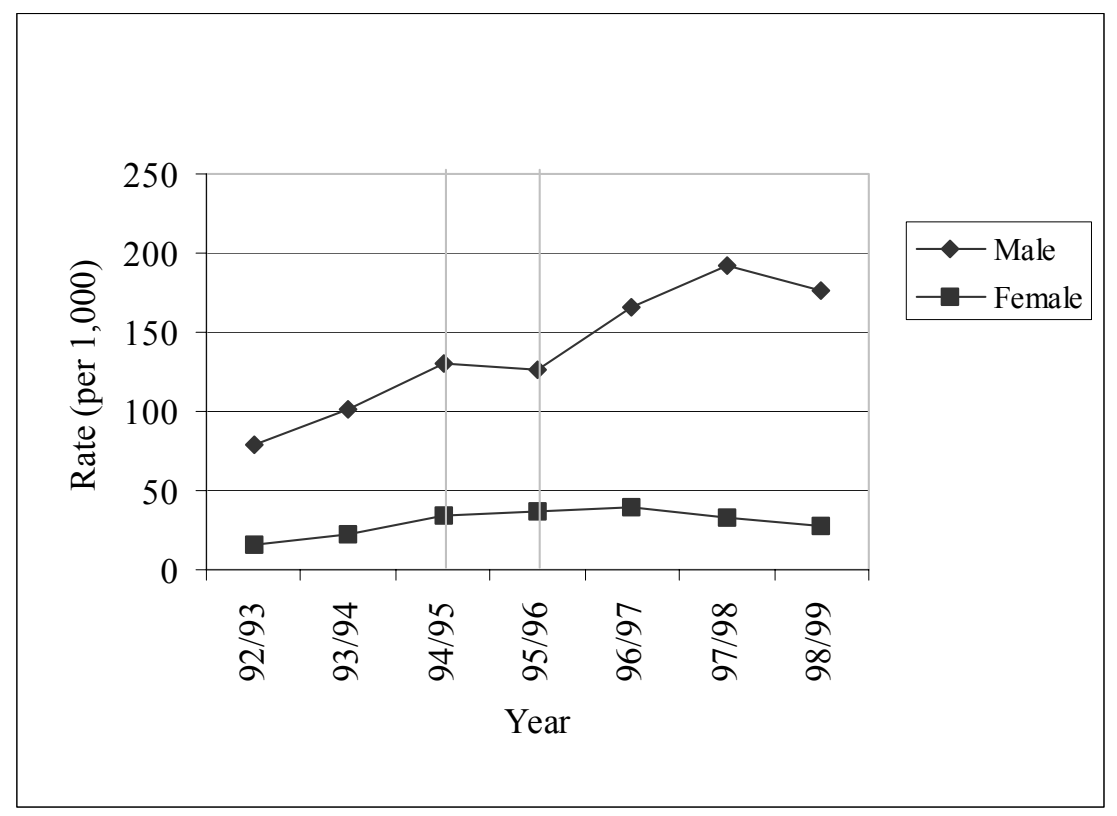

Source: BCS data.

Figure 3 presents juvenile offence rates by gender in Orange for the same period using NSW Bureau of Crime Statistics data. This figure indicates a steady increase in the crime rate for males in Orange from 1992 until 1999 with no significant difference in the 1995/6 period when compared to the prior and subsequent periods. This is in direct contrast to the results for Gosford. Again, there was no significant difference in the juvenile crime rate for females during the $1995 / 6$ period when compared to the prior and subsequent periods. 
Figure3: Juvenile Offence Rates by Gender in Orange

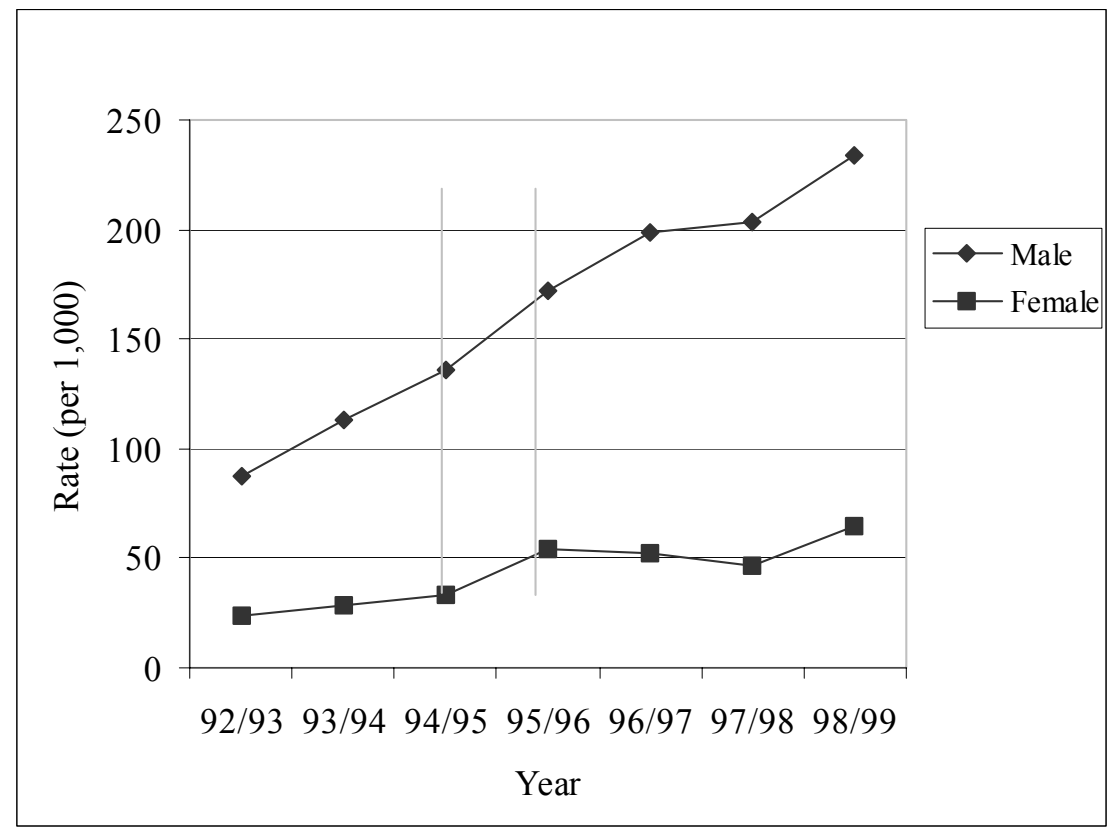

Source: BCS data.

On the basis of these results, the pilot scheme appears to have been successful in reducing the crime rate amongst the juvenile male population of Gosford but does not appear to have been a success amongst juvenile males in Orange.

\section{Juvenile Offence Rates by Age Groups}

Figure 4 represents juvenile offence rates by age groups in Gosford from 1992 until 1999 using NSW Bureau of Crime Statistics data. Three age groups were considered in the analysis: the 10-12 year age group, the 13-15 year age group and the 16-18 year age group. Figure 4 illustrates that in Orange for the year 1995/6, there was stability in crime rates for juveniles in the 13-15 year and the 16-18 year old categories when compared to the prior and subsequent periods. The change in the 10-12 year old category for the $1995 / 6$ period was negligible when compared to prior and subsequent periods. 
Figure 4: Juvenile Offence Rates by Age Groups-Gosford

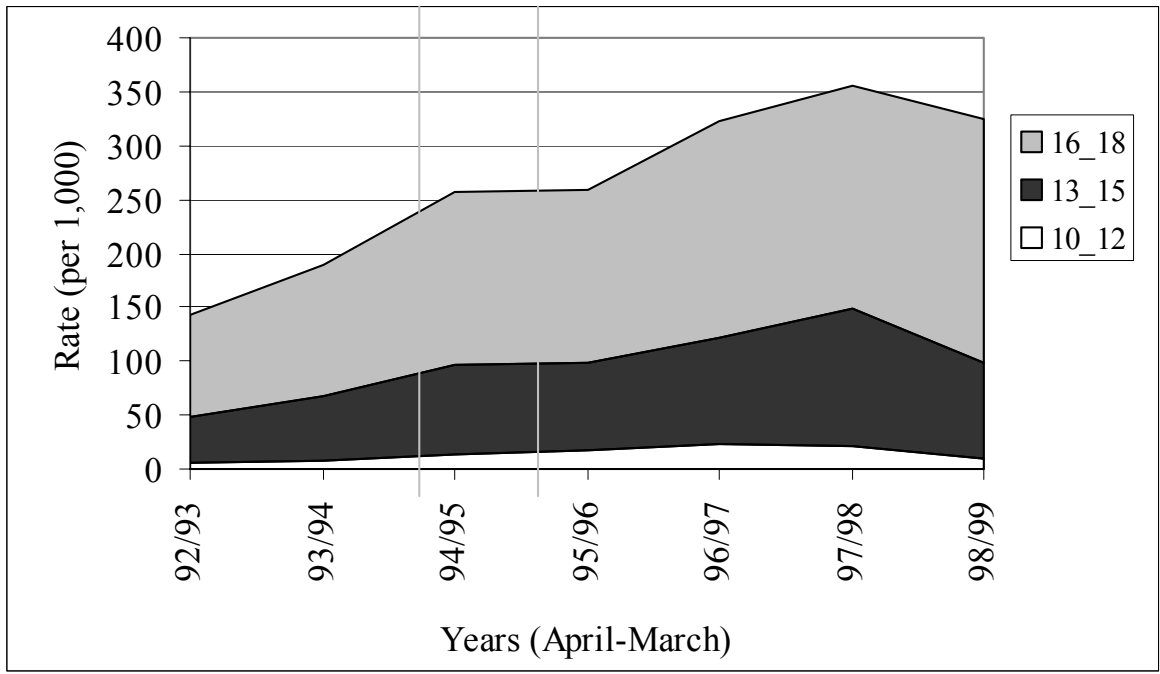

Source: BCS data.

Figure 5 represents juvenile offence rates by age groups in Orange using NSW Bureau of Crime Statistics data. Figure 5 indicates that the growth rate of crime for juveniles in the 13-15 year old and the 16-18 year old categories did not slow down in the period 1995/6 when compared to the prior and subsequent periods. Again, the change in the 10-12 year old category was negligible.

Figure 5: Juvenile Offence Rates By Age Groups-Orange

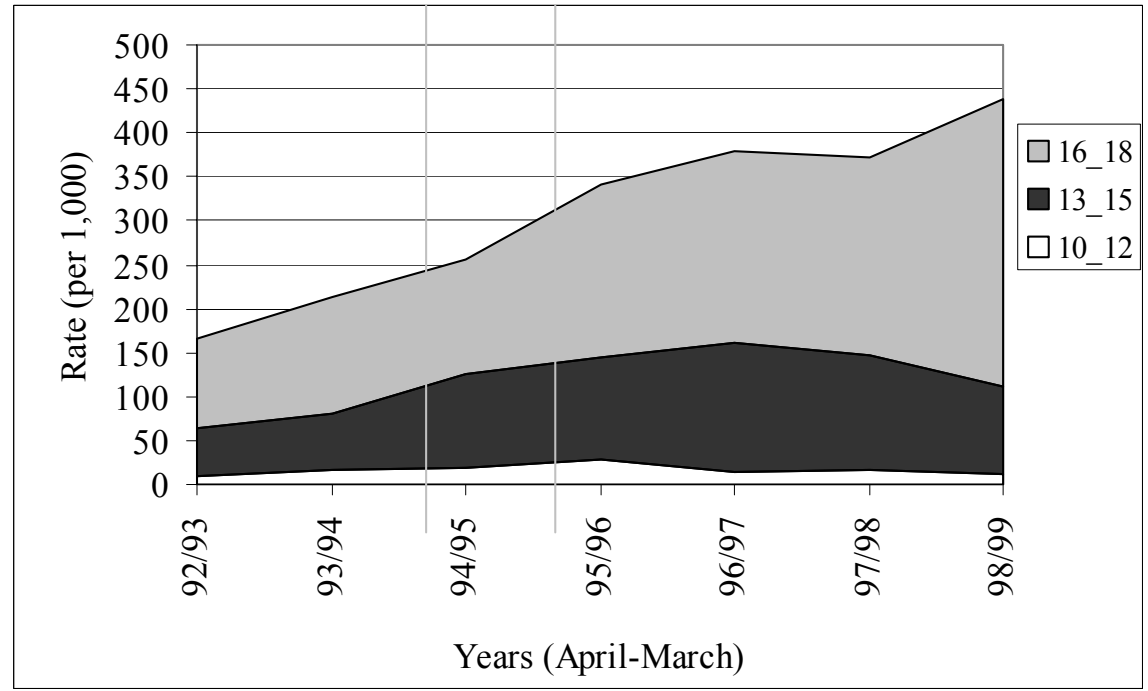

Source: BCS data. 
Data for NSW reflected similar patterns to that in Orange for all the three age groups.

On the basis of these results, the pilot scheme seems to have had an effect in decreasing the crime rates in the age groups 13-15 and 16-18 in Gosford, but did not have a noticeable effect on any age group in Orange.

\section{Discussion and Recommendations}

The perception after the pilot scheme was introduced into Orange and Gosford was that the scheme was a success in Orange (Evaluation Committee 1997:41-44 and Appendix C) but was not a success in Gosford (pp. 51-54 and Appendix C). The results of our analysis of the available statistical data support the opposite conclusion.

Why the pilot scheme can be claimed to be a success in Gosford and not in Orange on the basis of the available statistical data is open to conjecture. One or many of a number of factors might explain the reduction in juvenile crime rates in 1995/6 (Chan, 1994:35). One interesting anomaly, however, is that despite the pilot scheme having more support in Orange than in Gosford, our results would suggest this was not a significant factor in the scheme's success. We recommend that further research into the possible factors that reduced the rate of juvenile crime in Gosford needs to be done.

The pilot scheme as it operated in Gosford and Orange acted as the prototype for schemes that can now be introduced under new legislation, namely the Children (Protection and Parental Responsibility) Act 1997 (NSW). The NSW Coalition Government enacted this new Act shortly after the report by the Evaluation Committee into the Children (Parental Responsibility) Act 1994 (NSW) was handed down even though that Committee recommended that Part 3 of the 1994 Act not be re-enacted. Under the new legislation a local government area or part thereof can be declared an operational area by the NSW Attorney General upon that area's request (section 14(1,2)). The Attorney General cannot make such a declaration unless he or she is satisfied that adequate crime prevention or youth support initiatives are or will be available before the declaration takes effect (section 14(3)). Before making the declaration, the Attorney General should consider:

- whether the council has consulted with the local community, including young people and Aboriginals;

- the extent and nature of crime in the area;

- any crime prevention, youth support initiatives or safer community compacts;

- the impact on young people and availability of safe and appropriate recreational amenities for young people;

- the ability for police to carry out the scheme;

- the availability of appropriate refuge places; and

- whether the council has undertaken steps to include young people's needs in its local planning processes. 
The Attorney General must also consult with the Minister for Community Services and Minister for Police (section 14(4,5)).

Once a declaration is in force the police have very similar powers to remove juveniles from public places to that which they had under the Children (Parental Responsibility) Act 1994 (NSW) (sections 18, 19, 21 and 22). Both Orange and Gosford had the opportunity of becoming operational areas under the new Act without the need to seek a declaration by the Attorney General. Orange took up the option but Gosford declined.

Thus, despite the lack of objective evidence as to whether the pilot schemes were a success or not, the thrust of the schemes was re-enacted by the NSW government. The perception of the pilot scheme's success appears to have been relied on rather than any empirical evidence. As noted by the Australian Law Reform Commission quoted in Youth Justice Coalition (1990:98), community perceptions ought not to be the sole arbiter of what is the truth: 'It is impossible to understand the impact of legal measures without adequate statistical information' particularly when it comes to evaluating trial schemes for the reduction of crime.

Our study demonstrates the vital importance of proper and thorough evaluation of crime prevention schemes. The pilot scheme, unfortunately, fell into the normal situation about which the Australian Law Reform Commission commented (Youth Justice Coalition 1990:98):

Legislators have enacted statutes without attaching adequate arrangements for collecting data from which to gauge the effect of those measures, or test whether the legislative aims have been realised.

This paper endorses the conclusion drawn by Chan (1994:58) that

...rigorous evaluation of crime prevention programs is essential, but sadly lacking in many instances. Too often unrealistic claims or expectations are placed upon programs which have not been properly conceptualised, designed or implemented. Once implemented, programs are rarely carefully monitored and evaluated against their original claims. This 'routinisation of ignorance' allows the uncritical acceptance of impressionistic and emotive claims which are not substantiated by more carefully gathered evidence.

We recommend that whenever new crime prevention plans are instituted then proper evaluatory studies by which to judge the subjective and objective efficacy of that programme must be set up.

\section{References.}

Baker, J. (1998), Juveniles in Crime-Part 1: Participation Rates and Risk Factors, NSW Bureau of Crime Statistics and Research, Sydney. 
Chan, J. (1994), Preventing Juvenile Property Crime: A Review of the Literature, Juvenile Justice Advisory Council of NSW, Sydney.

Evaluation Committee on the Children (Parental Responsibility) Act 1994 (1997), Report, Parliament of New South Wales.

NSW Department of Juvenile Justice (1996), 1995/6 Annual Report, Department of Juvenile Justice, Sydney.

Parliament of NSW (Legislative Council) (1992), Fourth Report of the Standing Committee on Social Issues on Juvenile Justice in NSW, Parliament of New South Wales.

Youth Justice Coalition (1990), 'Kids in Justice: A Blueprint for the '90's', Full Report of the Youth Justice Project, Youth Justice Project, Surry Hills.

The authors would like to gratefully acknowledge the kind and efficient assistance of Garth Luke from the Department of Juvenile Justice in obtaining and interpreting statistical data. The authors are also grateful for useful comments by anonymous referees. 